\title{
Increased response of diastolic blood pressure to exercise in patients with coronary artery disease: an index of latent ventricular dysfunction?
}

Ioannis A Paraskevaidis, Dimitrios T Kremastinos, Antonis S Kassimatis, George K Karavolias, Giorgos D Kordosis, Zenon S Kyriakides, Pavlos K Toutouzas

\begin{abstract}
Objective-To determine whether an abnormal response of diastolic blood pressure during treadmill exercise stress testing correlated with the number of obstructed vessels and with left ventricular systolic function in patients with coronary artery disease.
\end{abstract}

Design-Diastolic blood pressure was measured invasively during exercise stress testing and coronary angiograms and left ventriculograms were obtained at rest in patients with coronary artery disease. The abnormal ( $\geqslant 15 \mathrm{~mm} \mathrm{Hg}$ ) diastolic blood pressure response was compared with the number of obstructed coronary arteries and with left ventricular systolic function.

Setting-Two tertiary referral centres.

Patients-50 consecutive patients (mean age 57 years) with coronary artery disease.

Main outcome measures-The increase in diastolic blood pressure during exercise and its correlation with the appearance and disappearance of ST segment deviation, resting left ventricular systolic function, and the number of obstructed coronary arteries.

Results-Group 1: 10 (20\%) patients (three with one, four with two, and three with three vessel coronary artery disease) (mean (SD) age 54.7(12) years) had an abnormal diastolic blood pressure response that appeared $1 \cdot 2(0 \cdot 3) \mathrm{min}$ before ST segment deviation and became normal $0.9(0.3)$ min after the ST segment returned to normal. Group 2: 40 $(80 \%)$ patients (12 with one, 16 with two, and 12 with three vessel coronary arteries disease) (aged 56.8 (8.2) years) had a normal diastolic blood pressure response to stress testing. The ejection fraction $(46.3(5) \%)$ and cardiac index $(2.6(0 \cdot 1)$ $\left.1 / \mathrm{min} / \mathrm{m}^{2}\right)$ in group 1 were less than in group $2 \quad(61.6 \quad(4.2) \%$ and $3.8 \quad(0.3)$ $1 / \mathrm{min} / \mathrm{m}^{2}$ respectively, $\left.p \leqslant 0.001\right)$. The end systolic volume was greater in group 1 than in group 2: $38 \cdot 7(0 \cdot 7) \mathrm{ml} / \mathrm{m}^{2} v 28 \cdot 2$ (2.1) $\mathrm{ml} / \mathrm{m}^{2}, \mathrm{p} \leqslant 0 \cdot 001$.

Conclusion-In patients with coronary artery disease an abnormal increase in diastolic blood pressure during exercise stress testing correlated well with left ventricular systolic function at rest but not with the number of obstructed coronary arteries. The abnormal response of diastolic blood pressure probably reflects deterioration of myocardial function.

(Br Heart F 1993;69:507-511)

The behaviour of arterial blood pressure during exercise stress testing has been much investigated. Systolic blood pressure has been extensively studied and has been shown to correlate with both myocardial oxygen consumption $^{1}$ and the number of obstructed coronary vessels, ${ }^{2}$ as well as with myocardial ischaemia itself. ${ }^{34}$ Though diastolic blood pressure has been studied in healthy individuals, in whom there is a small decrease caused by peripheral vasodilation, ${ }^{5}$ there is little information on patients with coronary artery disease.

Published reports suggest that in patients with coronary artery disease the abnormal increase in diastolic pressure during exercise stress testing correlates with the number of stenotic coronary arteries. ${ }^{67}$ But a more recent study postulates that this abnormal increase is due to myocardial dysfunction manifested during stress testing. ${ }^{8}$

We have investigated changes in diastolic blood pressure during exercise stress testing in patients with coronary artery disease by the most reliable method (intra-arterial measurement) and we have attempted to correlate these changes with both the number of obstructed coronary arteries and left ventricular systolic function at rest.

Patients and methods

We studied 50 consecutive patients (38 men and 12 women, mean (SD) age 57 (9) years) with coronary artery disease from the daily list of the stress testing laboratory. In 34 patients myocardial infarction had been diagnosed 3-6 months before (20 anterior septal, nine inferior and five non-Q) and the remaining 16 had been admitted to hospital eight months before with electrocardiographically and clinically confirmed myocardial ischaemia. The patients were in New York Heart Association (NYHA) class I-II (used as either functional or angina classification). All underwent stress testing with recording of a 
12 lead electrocardiogram followed by coronary angiography.

Inclusion criteria were an intact atrioventricular and intraventricular conduction system shown by electrocardiography; left ventricular wall thickness within normal limits shown by echocardiography; absence of unstable angina, acute or myocardial infarction in the previous three months, and arterial hypertension; and no difference in arterial blood pressure (measured by sphygmomanometer) between left and right arm of more than $10 \mathrm{~mm} \mathrm{Hg}$.

\section{STRESS TESTING}

Medication (except aspirin) was stopped at least four days before the examination. No patient was taking digoxin. A 12 lead electrocardiogram was recorded before the stress test with the patient supine and then seated and after $30 \mathrm{~s}$ of hyperventilation. A treadmill stress test was performed by the Bruce protocol. The electrocardiogram was recorded and arterial blood pressure, measured by sphygmomanometer, was estimated (for the same arm) by two cardiologists of equal experience and expertise each minute throughout the test and at $1,2,3,5$, and 10 minutes during the recovery period. The end point of the test was the achievement of maximum predicted heart rate $(220$-age), ST depression $\geqslant 1 \mathrm{~mm} 0.08$ $s$ after the $J$ point in five successive complexes, chest pain, or a reduction in systolic blood pressure.

\section{INTRA-ARTERIAL MEASUREMENT OF BLOOD PRESSURE}

In all patients intra-arterial blood pressure was measured by cannulation of the radial artery. If the sphygmomanometric blood pressure was different in the two arms the cannulation was done in the arm with the higher value. Allen's test was used to check collateral circulation before the radial artery was cannulated. ${ }^{9}$ After local anaesthesia (lignocaine) a fluid-filled cathether was placed in the radial artery. The arterial line was connected to a strain gauge by pressure monitoring tubing. The output of the strain gauge was displayed on an Electronics for Medicine VR 12 recorder through a Statham P23ID transducer. The paper speed was $25 \mathrm{~mm} / \mathrm{s}$. Systolic and diastolic arterial pressure were then measured directly after calibration of the tracing. The electrocardiogram (leads I and II) was recorded simultaneously. Diastolic and systolic blood pressure were measured as a mean value over five consecutive cycles. Each time the gradient of the treadmill was changed the transducer was repositioned, if necessary, to be at the same level as the heart. The diastolic blood pressure response was regarded as abnormal when there was an increase or decrease of $\geqslant 15 \mathrm{~mm} \mathrm{Hg} .^{5}$

\section{VENTRICULOGRAPHY AND ANGIOGRAPHY}

All patients underwent right and left heart catheterisation by Seldinger's method. Left ventriculography was performed in the left anterior oblique and right anterior oblique projections to determine end systolic volume, $\vec{\circ}$ end diastolic volume, and ejection fraction. Cardiac output was measured by Fick's method and the cardiac index was calculated. Stenosis of more than $75 \%$ of the diameter of the vessel was regarded as significant.

\section{STATISTICAL ANALYSIS}

We used the Statistical Package of Social $O$ Science (SPSS). The unpaired $t$ test was used -

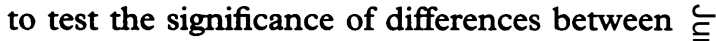
group mean values. Linear regression analysis was used to find relations between continuous variables. All data are expressed as mean (1SD). A p value less than 0.05 was regarded as statistically significant.

\section{Results}

The patients were divided into two groups according to their intra-arterial diastolic blood pressure response. Table 1 shows the haemodynamic and other findings for the two groups.

Group 1 consisted of $10(20 \%)$ patients who had an abnormal increase in diastolic pressure ( $\geqslant 15 \mathrm{~mm} \mathrm{Hg}$ ) during the stress test (figure). Nine of these had symptomatic (2.8 $(0.5) \mathrm{mm})$ and one had asymptomatic $(2 \cdot 2$ $\mathrm{mm}$ ) ST segment depression. The increase in diastolic pressure preceded the ST depression by $1.2(0 \cdot 2) \mathrm{min}$ and it became normal again $0.9(0.3)$ min after the ST segment returned to normal. Three patients had one, four had two, and three had three vessel coronary artery disease.

Table 1 Characteristics of the patients on exercise stress testing and haemodynamic data at rest (mean 1SD)

\begin{tabular}{|c|c|c|c|}
\hline & $\begin{array}{l}\text { Group 1 } \\
(n=10)\end{array}$ & $\begin{array}{l}\text { Group } 2 \\
(n=40)\end{array}$ & p value \\
\hline $\begin{array}{l}\text { Age (yr) } \\
\text { SBPmax }(\mathrm{mm} \mathrm{Hg}) \\
\Delta \text { SBP }(\mathrm{mm} \mathrm{Hg}) \\
\text { DBPmax }(\mathrm{mm} \mathrm{Hg}) \\
\Delta D B P(\mathrm{~mm} \mathrm{Hg}) \\
\text { DP }\left(\text { SBP } \times \text { HR } \times 10^{-2}\right) \\
\text { HR (beats/min) } \\
\text { ST depression }(\mathrm{mm}) \\
\text { EF }(\%) \\
\text { ESV }\left(\mathrm{ml} / \mathrm{m}^{2}\right) \\
\text { EDV }\left(\mathrm{ml} / \mathrm{m}^{2}\right) \\
\text { CI }\left(1 / \mathrm{min} / \mathrm{m}^{2}\right)\end{array}$ & $\begin{array}{c}54 \cdot 7(12) \\
182 \cdot 3(7 \cdot 7) \\
48(7) \\
89 \cdot 8(6 \cdot 8) \\
18 \cdot 5(2 \cdot 7) \\
270(30 \cdot 7) \\
148 \cdot 4(15 \cdot 5) \\
2 \cdot 6(0 \cdot 4) \\
46 \cdot 3(5) \\
38 \cdot 7(0 \cdot 7) \\
79(0 \cdot 8) \\
2 \cdot 6(0 \cdot 1)\end{array}$ & $\begin{array}{c}56 \cdot 8(8 \cdot 2) \\
176 \cdot 8(13 \cdot 5) \\
39 \cdot 5(13 \cdot 2) \\
73.6(6 \cdot 6) \\
0 \cdot 2(5 \cdot 4) \\
264 \cdot 1(32 \cdot 9) \\
149(11) \\
1.8(0 \cdot 9) \\
61.6(4 \cdot 2) \\
28 \cdot 2(2 \cdot 1) \\
79 \cdot 5(1 \cdot 9) \\
3.8(0 \cdot 3)\end{array}$ & $\begin{aligned} & N S \\
& N S \\
& N S \\
& \leqslant 0.001 \\
& \leqslant 0.001 \\
& N S \\
& N S \\
& \leqslant 0.001 \\
& \leqslant 0.001 \\
& \leqslant 0.001 \\
& N S \\
& \leqslant 0.001\end{aligned}$ \\
\hline
\end{tabular}

Group 1 had an abnormal diastolic blood pressure response.

Group 2 had a normal diastolic blood pressure response.

SBP, systolic blood pressure; DBP, diastolic blood pressure; EF, ejection fraction; DP, double product; ESV, end systolic volume; EDV, end diastolic volume; $\mathrm{CI}$, cardiac index. 

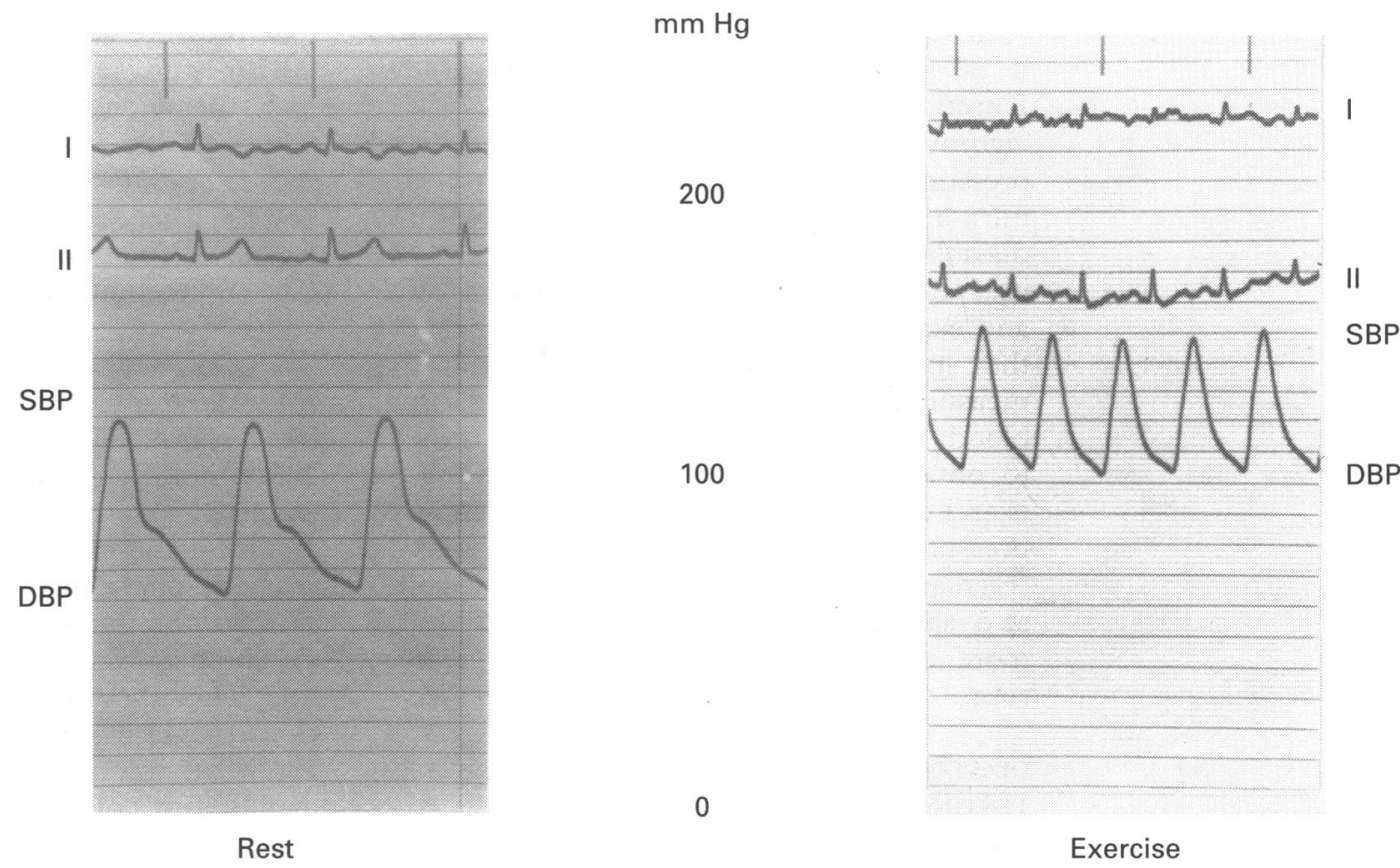

Increases in diastolic blood pressure (measured intra-arterially) during treadmill stress testing. SBP, systolic blood pressure; $D B P$, diastolic blood pressure.

Group 2 consisted of 40 patients (80\%) who had no abnormal increase in diastolic blood pressure. Nine had symptomatic ST segment depression $(2 \cdot 1(0.8 \mathrm{~mm})), 18$ had asymptomatic ST segment depression ( 1.6 $(0.5 \mathrm{~mm}))$, and $13 \mathrm{had}$ a normal stress test. Twelve patients had one, 16 had two, and 12 had three vessel coronary artery disease.

Table 2 shows the mean values of blood pressure at rest and during exercise, measured by sphygmomanometer and intra-arterially. Though there was a good correlation between the spygmomanometric readings of diastolic pressure and intra-arterial pressure at rest, there was no statistically significant correlation between the sphygmomanometric readings of diastolic pressure during exercise made by the two observers, or between the

Table 2 Measurement of arterial blood pressure $(\mathrm{mm} \mathrm{Hg})$ intra-arterially and by sphygmomanometer at rest and during treadmill exercise stress. Results are given for groups separately and combined (mean (SD))

\begin{tabular}{|c|c|c|c|c|}
\hline & & \multicolumn{2}{|c|}{ Sphygmomanometer } & \multirow{2}{*}{$\begin{array}{l}\text { Intra- } \\
\text { arterially }\end{array}$} \\
\hline & & Observer 1 & Observer 2 & \\
\hline \multicolumn{5}{|l|}{ Rest: } \\
\hline Total & Sys & $127 \cdot 6(6 \cdot 0)$ & $126 \cdot 8(6 \cdot 0)$ & $136 \cdot 6(7 \cdot 0)$ \\
\hline & Dias & $76 \cdot 2(5 \cdot 0)$ & $83 \cdot 4(9 \cdot 7)$ & $73 \cdot 0(5 \cdot 8)$ \\
\hline Group 1 & Sys & $125 \cdot 2(4 \cdot 0)$ & $124 \cdot 5(2 \cdot 9)$ & $134 \cdot 3(6 \cdot 7)$ \\
\hline & Dias & $73 \cdot 5(5 \cdot 5)$ & $83 \cdot 2(7 \cdot 8)$ & $71 \cdot 3(6 \cdot 8)$ \\
\hline Group 2 & Sys & $127 \cdot 8(6 \cdot 3)$ & $127 \cdot 4(6 \cdot 6)$ & $137 \cdot 3(7 \cdot 0)$ \\
\hline \multicolumn{5}{|l|}{ Exercise: } \\
\hline Total & Sys & $175 \cdot 0(11 \cdot 6)$ & $175 \cdot 8(12 \cdot 0)$ & $178 \cdot 0(12 \cdot 7)$ \\
\hline & Dias & $76.5(5.4)$ & $81 \cdot 9(10 \cdot 1)$ & $76 \cdot 8(9 \cdot 3)$ \\
\hline Group 1 & Sys & $180 \cdot 7(6 \cdot 0)$ & $180 \cdot 1(6 \cdot 9)$ & $182 \cdot 3(7 \cdot 7)$ \\
\hline & Dias & $73 \cdot 6(6 \cdot 2)$ & $83.0(10 \cdot 6)$ & $89 \cdot 8(6 \cdot 8)$ \\
\hline Group 2 & Sys & $174 \cdot 4(12 \cdot 4)$ & $174 \cdot 8(12 \cdot 8)$ & $176 \cdot 8(13 \cdot 5)$ \\
\hline & Dias & $77 \cdot 3(5 \cdot 0)$ & $81 \cdot 6(10 \cdot 2)$ & $73 \cdot 6(6 \cdot 6)$ \\
\hline
\end{tabular}

Diastolic blood pressure correlations.

Rest

Total $(\mathrm{n}=50)$ Ob1-Ob2, $r=0.52, \mathrm{p} \leqslant 0.001$; Ob1-IA, $r 0.84, \mathrm{p} \leqslant 0.001$; Ob2-IA $r=0.63$,

$\mathrm{p}<0.001$

Total ( $\mathrm{n}=50)$ Ob1-Ob2, $\mathrm{p}=\mathrm{NS} ; \mathrm{Ob} 1-\mathrm{IA}, \mathrm{p}=\mathrm{NS} ; \mathrm{Ob} 2-\mathrm{IA}, \mathrm{p}=\mathrm{NS}$.

Group $1(n=10)$ Obl- $(n)$,

Group $2(n=40)$ Ob1-Ob2, $p=N S ; O b 1-I A, p=N S ; O b 2-I A, p=N S$.

Sys, systolic blood pressure; Dias, diastolic blood pressure. sphygmomanometric and intra-arterial diastolic pressure readings, either for group 1 and 2 separately or the two groups combined. When all patients of both groups were reclassified on the basis of the median exercise diastolic blood pressure $(75 \mathrm{~mm} \mathrm{Hg}$ ) there was no correlation in either the lower (26 patients) or higher (24 patients) value groups, either between observers $(r-0.03, N S ; r$ $0 \cdot 09$, NS, respectively) or between sphygmomanometer and intra-arterial values ( $\mathrm{r} 0.03$, -0.07 , NS and $\mathrm{r}-0.1,0.3$, NS, respectively.)

Only three of the haemodynamic variables were significantly different between the two groups: the ejection fraction and cardiac index were lower in group 1 than in group 2 whereas the end systolic volume was higher (table 1). Also group 1 showed greater ST segment depression than group 2 (table 1). There were no significant differences between the groups for the number of obstructed coronary arteries.

\section{Discussion}

Systolic blood pressure has been shown to correlate well with myocardial ischaemia $^{1-4}$-a decrease of $\geqslant 10 \mathrm{~mm} \mathrm{Hg}^{10}$ reflects severe (two or three vessel) coronary artery disease. ${ }^{12}$ Reports on the behaviour of diastolic pressure during stress testing are contradictory, however, with some groups ${ }^{67}$ maintaining that an abnormal increase $(\geqslant 15$ $\mathrm{mm} \mathrm{Hg}$ ) correlates with the number of stenotic arteries while others ${ }^{8}$ claim that it correlates with left ventricular systolic function.

METHODS OF MEASUREMENT

In earlier studies diastolic blood pressure was measured by sphygmomanometer, a method 
with several inherent objective problems. Also it is not easy to detect the 4 th or 5 th Korotkoff sounds in someone who is moving vigorously. In our study we measured blood pressure both by sphygmomanometry and intra-arterially. The conflicting values for diastolic blood pressure measured by two independent investigators with equal practice and expertise and the lack of accord between the sphygmomanometric and intra-arterial measurements clearly show that diastolic blood pressure measurements-are difficult to obtain by sphygmomanometry during an exercise test and bear no direct relation to pressure in the artery. Statistical analysis (median exercise diastolic blood pressure) also showed that the observers became no more consistent as diastolic blood pressure rose.

\section{DIASTOLIC PRESSURE CHANGES DURING STRESS} TESTING

When we used the most accurate way of determining diastolic blood pressure - that is, intra-arterial measurements ${ }^{112}$-we found that $20 \%$ of our patients showed an abnormal increase during stress testing. This is a higher proportion than reported by others ${ }^{67}$ (probably because of the different methods used). Also, in contrast to these earlier studies, we found that the increase in diastolic pressure in patients with coronary artery disease correlated, not with the number of obstructed coronary vessels but with the degree of left ventricular dysfunction. This discrepancy is not unexpected because myocardial ischaemia is not proportionate to the atherosclerotic damage to the coronary arteries, ${ }^{13}$ but mainly to the pathophysiology of the coronary arteries, ${ }^{1415}$ the coronary reserve, and the pressure drop across the stenosis. ${ }^{1316}$ Furthermore, not only does coronary angiography not give information about the pathophysiology of the vessels, it does not even accurately reflect the degree of stenosis itself ${ }^{17} 18$ or its development. ${ }^{13}$

Our findings also differ from those of earlier studies ${ }^{67}$ in that we found that patients with coronary artery disease with an abnormal increase in diastolic blood pressure during exercise had a significantly lower ejection fraction and cardiac index and a higher end systolic volume than patients with normal diastolic pressure. The values of these variables, bordering on the pathological at rest, probably change for the worse during an exercise test, ${ }^{19}$ leading to a further increase in peripheral vascular resistance, ${ }^{20}$ pulmonary artery pressure, ${ }^{20}$ and left ventricular end diastolic pressure. ${ }^{21}$ The result of these haemodynamic changes seems to be an increase in diastolic pressure.

Recent studies ${ }^{8}$ support these findings by showing that when patients with an abnormal increase in diastolic pressure during exercise have an improved ejection fraction after coronary artery bypass subsequent stress tests produce no abnormal fluctuations in diastolic pressure. Whereas if the bypass does not improve ejection fraction the increase in dias- tolic pressure continues to occur.

Our study also showed, as did another, ${ }^{8}$ that the increase in diastolic pressure in patients with coronary artery disease during stress testing precedes the electrocardiographic changes. We do not think that this finding is paradoxical because it reinforces $\underline{\underline{T}}$ the connection between diastolic pressure $\frac{T}{\Phi}$ and left ventricular function, because haemodynamic changes are known to precede elec- $c$. trocardiographic findings. We also found that the restoration of diastolic pressure followed $\stackrel{\text { क }}{7}$ the restoration of the electrocardiographic? changes. This shows that the course followed $\frac{\bar{\sigma}}{\overline{5}}$ by the pathophysiological mechanism in the $\frac{\vec{\Phi}}{\widetilde{\alpha}}$ recovery of the myocardium from ischaemia $\propto$ seems to be the reverse of the sequence of its appearance. Recent studies confirm this find- $\overrightarrow{0}$ ing. They showed that after the exercise elec- $\overrightarrow{-}$ trocardiogram returned to normal both the ${ }_{\sigma}^{\omega}$ abnormal mobility ${ }^{22}$ and the pathological metabolism $^{23}$ of the myocardium persisted for a long time.

We found that patients with coronaryor artery disease and myocardial dysfunction at $\mathrm{V}$ rest had an abnormal increase in diastolic음 blood pressure during exercise stress testing. $\vec{c}$ This probably reflects the haemodynamic changes occurring during the test. Though $\widetilde{D}$ we did not study the actual haemodynamic $\overrightarrow{0}$ changes during stress testing, we believe that $\omega$ the determination of diastolic pressure couldo provide significant information about resting? myocardial dysfunction in patients with coro- $\frac{\bar{O}}{\mathrm{O}}$ nary artery disease.

\section{Clinical applications}

Though the intra-arterial measurement of pressure is, unfortunately, not entirely free of complications, ${ }^{24}{ }^{25}$ none was found in any of our patients. This is explained by the short duration of the arterial cannulation (14-24: $\mathrm{min}$ ) and on the basis of this result we recommend the wider use of this technique. The lack of any significant correlation between the sphygmomanometric readings of diastolico pressure during exercise made by the two observers, or between the sphygmomanomet-을. ric and intra-arterial pressure readings, shows N that the intra-arterial measurement of dias-tolic pressure can be relied upon to give a $N$ true result. While the changes in the ST seg- $\omega$ ment during exercise are the reference $\operatorname{stan}-$ dard for the diagnosis of myocardiale ischaemia, the fact that the abnormal increase in diastolic pressure preceded the electrocar- diographic changes, while its return to normal $\frac{0}{0}$ followed the restoration of the normal elec- $\stackrel{\mathbb{\Phi}}{\Omega}$ trocardiogram, is probably a reflection of the $\frac{\overrightarrow{\mathbb{D}}}{\mathrm{O}}$ haemodynamic condition of the myocardium. $\frac{\Omega}{\sigma}$ To what extent the haemodynamic changes in the myocardium, expressed apparentlyo through an increase in diastolic pressure, are due to a hibernating or stunned myocardium remains to be elucidated.

We thank Miss Theano Zachariadou for her secretarial support. 
1 Ellestand HM. Stress testing, 3rd edition, Ellestand HM. Blood pressure measurements during exercise. Philadelphia: F A Davis. 1986;355-66.

2 Morris SN, Phillips JF, Jordan JW, McHenry PL. Incidence and significance of decrease in systolic blood pressure during graded treadmill exercise testing. $A m \mathcal{F}$ pressure during graded

3 Irving JB, Bruce RA, DeRouen TA. Variation in and significance of systolic pressure during maximal (treadmill) testing: relation to severity of coronary artery disease and cardiac mortality. Am $\mathcal{f}$ Cardiol 1977;39:841-8.

4 Thomson JB, Keleman MH. Hypotension accompanying the onset of exertional angina. A sign of severe compromise of left ventricular blood supply. Circulation 1975;52:28-32.

5 Wolthuis RA, Froelicher VF, Fischer J, Triebwasser JH. The response of healthy men to treadmill exercise. Circulation 1977;55:153-7.

6 Akhras F, Upward J, Jackson G. Increased diastolic blood pressure response to exercise testing when coronary artery disease is suspected $A n$ indication of severity. $\mathrm{Br}$ Heart $f 1985 ; 53: 598-602$.

7 Sheps SD, Ernst CJ, Briese WF, Myerburg RJ. Exerciseinduced increase in diastolic pressure: Indicator of induced increase in diastolic pressure: Indicator of severe coro

8 Akhras F, Jackson G. Raised exercise diastolic blood pressure as indicator of ischaemic left ventricular dysfuncsure as indicator of ischaemic

9 Allen EV. Thromboangiitis obliterans: methods of diagnosis of chronic arterial lesions distal to the wrist with illustrative cases. Am F Med Sci 1929;178:237-44.

10 Willerson JT, Hillis LD, Buja LA. Ischemic heart disease. New York: Raven Press, 1983;171-9.

11 Bruner JMR, Krenis LJ, Junsman JM, Sherman AP. Comparison of direct and indirect methods of measuring arterial blood

12 Kyriakides ZS, Kremastinos D, Rentoukas E, Vavelidis J, Damianou C, Toutouzas $P$. Non invasive determination of the left ventricular end-systolic pressure. Int 7 Cardiol 1991;33:267-74.

13 White CW, Wright CB, Doty DB, Hiratza LF, Eastham $\mathrm{CL}$, Harrison DG, et al. Does visual interpretation of the coronary angiogram predict the physiologic impor- tance of coronary stenosis? $N$ Engl $f$ Med 1984; 310:819-24.

14 Furehgott RF, Zawadzki JV. The obligatory role of endothelial cells in the relaxation of arterial smooth muscle by acetilcoline. Nature 1980;288:373-6.

15 Gaur $P$, Alexander PW. New insights into the cellular mechanisms of vasospasm. Am $\mathcal{F}$ Cardiol 1985.56:11E $15 \mathrm{E}$.

16 Legrand U, Hodgson JMCB, Bates ER, Aueron FM, Mancini GB, Smith JS, et al. Abnormal coronary flow reserve and abnormal radionuclide exercise tests in patients with coronary angiograms. F Am Coll Cardiol 1985;6:1245-53.

17 Arnett EN, Isner JM, Redwood CR, Kent K, Baker WP, Ackerstein $\mathrm{H}$, et al. Coronary artery narrowing in coronary heart disease. Comparison of cineangiographic and necropsy findings. Ann Intern Med 1979;91:350-6.

18 Galbraith JE, Murphy ML, Desoysa N. Coronary angiogram interpretation. Interobserver variability. ҰAMA 1981;240:2053-9.

19 Rerych SK, Scholz PM, Newman GE, Sabiston DC, Jones RH. Cardiac function at rest and during exercise in normals and in patients with coronary artery disease. Ann Surg 1978;187:449-64.

20 Ellestand HM. Stress testing, 3rd edition, Ellestand HM. Physiology of cardiac ischemia. Philadelphia: FA Davis. Physiology of

21 Boucard RJ, Gault JH, Ross J Jr. Evaluation of pulmonary arterial end-diastolic pressure in patients with normal and abnormal left ventricular performance. Circulation 1971;44:1072-9.

22 Kloner AR, Allen J, Cox AT, Zheng U, Ruiz CE. Stunned left ventricular myocardium after exercise treadmill testing in coronary artery disease. $\mathrm{Am} f$ Cardiol 1991;68:329-34.

23 Camici P, Araujo LI, Spinks T, Lammertsma AA, Kaski JC, Shea MJ, et al. Increased uptake of 18 F-fluorodeoxyglucose in postischemic myocardium of patients with exercise induced angina. Circulation 1986;74:81-8.

24 Marshall G, Edelstein G, Hirschman CA. Median nerve compression following radial arterial puncture. Anesth Analg 1980;59:953-4.

25 Wyatt R, Glaves I, Cooper DJ. Proximal skin necrosis after radial-artery cannulation. Lancet 1974;ii:1135-8. 